\title{
QUO VADIS WATER QUALITY MANAGEMENT IN CENTRAL AND EASTERN EUROPE?
}

László Somlyódy

International Institute for Applied Systems Analysis

Laxenburg, Austria

RR-96-12

September 1996

Reprinted from Water Science Technology, Volume 30, No. 5, pp. 1-14, 1994.

INTERNATIONAL INSTITUTE FOR APPLIED SYSTEMS ANALYSIS Laxenburg, Austria 
Research Reports, which record research conducted at IIASA, are independently reviewed before publication. Views or opinions expressed herein do not necessarily represent those of the Institute, its National Member Organizations, or other organizations supporting the work.

Reprinted with permission from Elsevier Science Ltd, The Boulevard, Langford Lane, Kidlington OX5IGB, UK.

Copyright (C)1994 IAWQ

All rights reserved. No part of this publication may be reproduced or transmitted in any form or by any means, electronic or mechanical, including photocopy, recording, or any information storage or retrieval system, without permission in writing from the copyright holder.

Printed by Novographic, Vienna, Austria. 


\section{Foreword}

The current focus of IIASA's Water Resources Project is water quality management in Central and East European (CEE) countries undergoing political, social, economic, and institutional transition. Unlike in developed Western countries, here the policy dilemma is characterized by the fact that many diverse pollution problems should be handled at the same time with only limited financial resources available.

This situation raises a number of questions. Are the existing problems different from those previously observed in the West? To what extent can Western management experiences be utilized? What goals and standards should be set, and what strategies should be followed? What is the likely time horizon for achieving the desired water quality changes? How much would achieving these objectives cost? More specifically, how can policies be developed that are cost-effective in the short run and can be expanded over the transition period as the economies improve?

This paper addresses some of these issues. In related policy-oriented research, completed in mid-1996, two river basin water quality decision support systems were developed and applied in four case study regions in CEE countries to determine the most important elements of future short- and long-term strategies. 


\title{
QUO VADIS WATER QUALITY MANAGEMENT IN CENTRAL AND EASTERN EUROPE?
}

\author{
L. Somlyody $\dagger$ \\ International Institute for Applied Systems Analysis (IIASA), A-2361 Laxenburg, \\ Austria
}

\begin{abstract}
Central and Eastern European (CEE) countries are going through unique political, economic, institutional, and social changes associated with the heritage of serious pollution problems from the past. The purpose of this paper is to analyze the water quality management strategies CEE countries may take including the rationale of introducing Western policies in the short run. The policy to be selected must be viable under the existing pressing financial conditions and should feasibly be expanded towards a long-term sustainable scenario as economy improves. As a basis the present economic, social, and institutional setting is outlined, and the state of water quality and the role of emissions of various origins are summarized. A special focus is devoted to municipalities with low and unbalanced levels of infrastructure; the development of these infrastructures could be aburden even for stable economies. An overview and evaluation are given for the water supply, sewerage, and wastewater treatment for urban areas with populations greater than 25,000 in five countries of the CEE region together with a discussion of legislation issues. Major elements of costeffective development strategies are discussed and illustrated by examples. They incorporate improved demand management and the closing of material cycles, the upgrading of wastewater treatment facilities to match the level of sewerage, the application of regionally variable effluent (and/or ambient) water quality standards and their gradual tightening based on a river basin approach, the innovative selection of combined chemical-biological technologies (for both upgrading and new design) depending on local conditions and the multi-stage development of wastewater treatment plants. The policy suggested for the next couple of decades is characterized by a number of non-uniformities which raises considerable implementation challenges.
\end{abstract}

\section{KEYWORDS}

Central and Eastern Europe; water quality management strategies; river basin management; cost-effective municipal wastewater treatment; scheduling; phased investments; ambient and effluent water quality standards; legislation; institutions.

\section{INTRODUCTION}

Central and Eastern European (CEE) countries are going through enormous political, economic, and social changes; the nature of which is unique in history. The outcome of the exercise is not yet known, and two to three decades can be needed to see where the present transition leads. As far as environment and water pollution are concerned, the heritage from the past forty years is serious. It is characterized by a high level of

† On leave of abscence from the Water Resources Research Center (VITUKI), Budapest and the Budapest University of Technology. 
water contamination, the co-existence of problems caused by traditional and toxic pollutants as well as point and non-point sources, and the presence of local and regional (international) water resources problems (such as the Baltic Sea or the Danube). Additional difficulties are caused by the past contamination of soil, sediment, and groundwater (the vicinity of earlier industrial and military plants really act as chemical time bombs), which presents the issue of a costly and slow rehabilitation.

In spite of the above features, water pollution problems of the CEE region should not be considered unique in a technical sense. Similar situations existed in industrialized regions of the West about thirty years ago (e.g. the Ruhr Gebiet), and there is evidence that tools and technologies are available for the clean-up. The uniqueness stems from the coincidence of the need to handle the above serious issues and the very specific political, economic, and social conditions.

The past economic and environmental policies failed in Central and Eastern European countries, and there is both an obvious desire and a pressing need to develop a better policy. To follow and join the "West" (comprising quite a broad range of different strategies) seems to be a logical choice which is in harmony with political goals of various CEE governments. But is this policy really feasible? Are not too many dissimilarities prohibiting a one to one application? What methodologies and tools can be employed other than those stemming from the practice of the Western world? What technologies emerge from the experience of the West for the CEE region? Overall, what approach should be taken and what is a realistic time scale for introducing a new policy?

The present paper addresses some of the above issues. The organization is as follows. First, we illustrate the flavour of the present economic, social, and institutional setting. This will be followed by a discussion on the present state of water quality and emissions with a strong focus on municipalities. Next, we analyze major elements of both cost-effective management strategies and implementation challenges. The paper is completed by conclusions.

\section{ECONOMIC, SOCIAL, AND INSTITUTIONAL ISSUES}

Public awareness of environmental matters in the CEE region has been growing during the past couple of years. If public opinion polls show environment to have a lower priority, it is because other issues are so pressing: growing unemployment (close to $15 \%$ in several countries) and inflation, increasing prices and low salaries, bread-and-butter worries and so forth, which reduces willingness to pay for solving environmental and water pollution problems. The attitude of most of the CEE governments is similar: environmental management has a low priority since economic restructuring including privatization (the level of which exceeded $40 \%$ in several countries during the past three years), is considered more important,and focusing on both at the same time seems to be too difficult a task.

The costs of cleaning up the environment in CEE countries are tremendous. The per capita cost for meeting surface water quality standards of the European Community can be estimated to be a couple of thousand USD (leading to several hundred thousand million USD for Poland, the Czech Republic, Slovakia, Hungary, Romania, and Bulgaria), and needs are equally pressing for air quality control and waste management.

On the resource side, the per capita GDP is one-fifth to one-tenth of developed Western European countries. Various estimates for 1992 range for the above six countries between 700 USD and 3,50) USD (the trend is still declining); the lowest value applies to Romania and the highest to Hungary (it is noted that GDP figures depend on the methodology adopted, and the so-called purchase power shows a somewhat better picture). The above domain covers also Eastern European follow-up countries of the former Soviet Union (which are characterized by many additional uncertainties). Incomparison, the corresponding figures for Portugal, Spain, and Austria in 1992 were about 6,000 USD, 12,000 USD, and 20,000 USD, respectively.

The comparison of costs and resources suggests that the per capita water quality control cost may exceed the per capita gross domestic product in several countries, which is a clear indication that: 
governments may not be willing or able to cover the above costs in the immediate future,

the time horizon of any country-wide control policy must be a rather long period (i.e. several decades),

setting and scheduling of water quality priorities and goals are critical tasks.

In principle, countries in the region could borrow money for water pollution control. However, such a policy would not be wise (and governments indeed avoid it) as the national debts are already high (between $30 \%$ and $80 \%$ of the GDP). Loans will likely be (and should be) taken primarily for animating economy and industrial modernization (the reduction in industrial production between 1990 and 1992 was 30-50\% for the countries mentioned above).

Some of the Western countries spent about $1 \%$ of their GDP alone for the development of sewerage and wastewater treatment during the past twenty years and achieved remarkable results. To realize a similar development path, CEE countries should utilize at least 5\% of the GDP for the same purpose, but that is an unlikely option. The examples of Portugal, Spain, and simple estimates seem to suggest that a doubling of the GDP (used as a measure to improve the conditions of environmental investments) will require about two decades. Thus, one strong conclusion at this stage is that water quality management in CEE countries faces a much longer transition period than generally believed (2-3 decades) to reach water quality values close to Western norms. This is perhaps not a surprise if we consider both the long time already passed and the time still needed for Western European countries to meet standards of the European Community. The other conclusion (which will be stressed several times later on) is that a feasible strategy should be based on costeffectiveness in the short run, leaving open possibilities for gradual extensions in the long run.

The rationale of the above strategy is manifold. It avoids both the immediate introduction of a costly minimum discharge policy and the further high contamination of the water environment which would require increasingly more expensive solutions later on. It utilizes features of existing water management systems (which though are somewhat "distorted" from being developed on the basis of "specific" principles of centrally-planned economies) but does not necessarily justify an immediate, drastic re-shaping. Thus, time is available to develop a new long-term control policy.

Any new strategies should be launched under conditions of the on going dramatic transition. Some of the key elements of this process are as follows:

Centralized strategic and financial planning by the state has been almost completely abandoned, and there is a strong movement towards decentralization and privatization;

The institutional system is undergoing significant change, both abrupt and gradual, leading to a significantly increased role for local governments, the creation of new river basin authorities (for example in Poland) and environmental agencies, the disappearance of state owned regional water and wastewater companies (often without adequate replacements), and division of water-quantity and water-quality management functions into separate water and environmental ministries and district authorities (e.g. in Hungary and Russia);

Responsibility for water supply and treatment and ownership of the infrastructure is being transferred to municipalities;

Decision making has been largely decentralized. Due to a lack of experience and institutional structure, decentralization can lead to rather peculiar schemes, particularly if financing is also involved. For example, the planned construction of a wastewater treatment plant may now involve decision making by the state and local governments, several ministries (water, environment, public health, finance, etc.), their inspectorates and regional authorities, water works, and so on;

New environmental legislation is being gradually introduced; 
Foreign companies and capital have entered the market in different ways. These have both positive and negative repercussions. Transfer of knowledge in certain fields (management, operation, environmental impact assessment, auditing, etc.) and provision of well proven technologies are beneficial. On the other hand, selling of outdated, cheap, and unreliable methods can have long-term negative impacts.

\section{WATER QUALITY AND THE ROLE OF DIFFERENT EMISSIONS}

Most waters in CEE countries serve as recipients of untreated or inadequately treated effluents and sources for water supply. The quality is rather deteriorated, and often more than half of the total monitored river length belongs to the poorest water quality class of that country, which is the case for Poland, Slovakia, and Bulgaria. The situation is better in Hungary, mostly due to the higher dilution rate. The most noteworthy problems include high $\mathrm{BOD}_{5}$ levels associated with poor dissolved oxygen conditions, bacterial contamination, high ammonia and nitrate concentrations endangering water supplies, high phosphorus and nitrogen concentrations in rivers, large nutrient loads to lakes and seas, and high algal biomass, salinity, and serious heavy metal contamination in industrialized regions. For the sake of illustration, we note that our survey (see later) showed that the average low-flow $\mathrm{BOD}_{5}$ value of receiving rivers downstream of urban areas above 25,000 population in five countries (Poland, the Czech Republic, Slovakia, Hungary, and Bulgaria) was about $20 \mathrm{mg} / \mathrm{l}$ with extremes close to $200 \mathrm{mg} / \mathrm{l}$.

The ongoing economic changes (and in some aspects, crises) significantly (but variably) affect water pollution from various economic sectors. The decline in industrial production and plant shutdowns has caused some heavily contaminated rivers to improve by one or two water quality classes. For instance, the annual average $\mathrm{BOD}_{5}$ level of the Sajo river in Hungary has dropped by about $5 \mathrm{mg} / \mathrm{l}$ from 1990 to 1991 (the maximum value decreased from around $30 \mathrm{mg} / 1$ to less than $10 \mathrm{mg} / \mathrm{l}$ ). Decreased use of fertilizers in agriculture has reduced nutrient loads, although to a smaller extent, due to earlier accumulation in the top soil layer.

These changes, which have not resulted from any systematic management actions, illustrate the new opportunity to couple environmental management with industrial and agricultural transformation. In industry, this would mean the reduction of water consumption, reuse, recycling, and the introduction of advanced production technologies rather than end-of-the-pipe type control (which could lead to wasted investments under the present unpredictable fate of many industrial plants). How this opportunity will be realized remains to be seen.

Unlike industrial and agricultural pollutions, urban and municipal emission shave hardly been affected by the current economic changes. The investment needed to improve existing systems to a level far below the standards in Western Europe would be an enormous burden, even for stable economies. Thus, the dilemma is how to develop a cost-effective strategy which supports the economic transition without exacerbating existing social problems caused primarily by the low per capita GDP.

\section{PRESENT STATUS OF WATER SUPPLY, SEWERAGE, AND MUNICIPAL WASTE WATER TREATMENT\}}

In the frame of preparing the Environmental Action Programme for Central and Eastern Europe (1993) under the coordination of the World Bank, detailed data collection and analysis were performed to demonstrate major elements of a cost-effective municipal wastewater management strategy for the region (Somlyody, in press). Data collection (characterizing the state of the late eighties) incorporated information on water supply, the collection network, wastewater treatment, sludge handling, and receiving waters (both quantity and quality). 362 municipalities in five countries (Poland, the Czech Republic, Slovakia, Hungary, and Bulgaria) with a total population of 35 million (representing $50 \%$ of the total population and $70 \%$ of the urban population) were assembled. Data were collected for all towns with populations greater than $25,0(0)$. In addition, partial data were gathered for a considerable number of towns in Poland with populations greater than 10,000. Aggregated data were collected for the remaining population in each country and 
estimates were used if information was missing. A summary is given in Table 1. Conclusions from the table and from the entire survey are drawn as follows (for details see Somlyody, in press).

TABLE 1. Summary Information on Water Supply, Sewerage and Wastewater Treatment

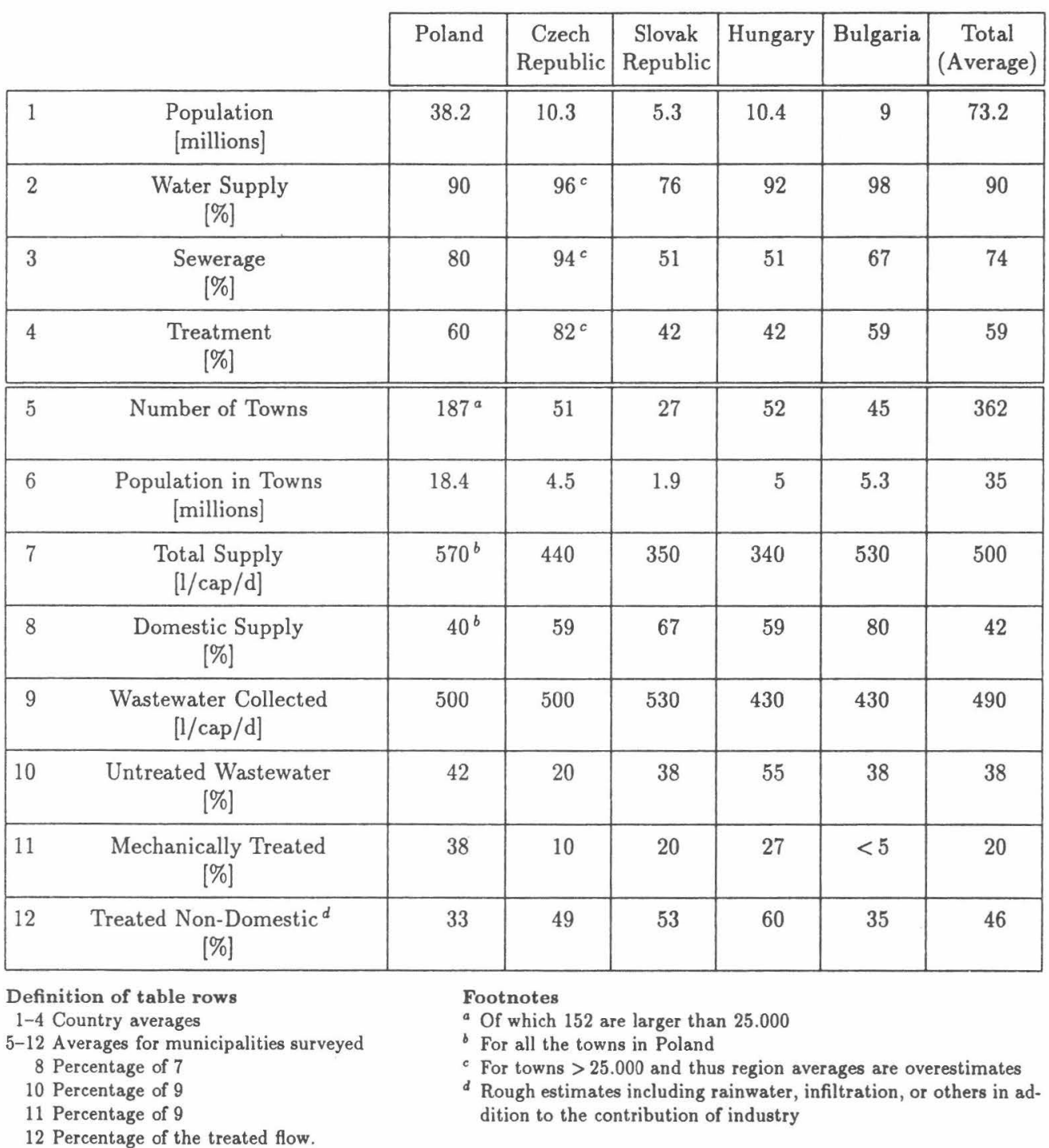

\section{General Observations}

The overall level of water supply is quite good (at least insofar as quantity is concerned) and, on average, sewerage is adequately developed. However, the level of sewage treatment is poor, particularly if one considers that less than $50 \%$ of the wastewater received secondary treatment. The average treatment system efficiency over the five countries is approximately $70 \%$. Thus, considering the fraction of wastewater not 
receiving secondary treatment and the efficiency of treatment for wastewater receiving treatment, we can estimate that only about $35 \%$ of the influent $\mathrm{BOD}_{5}$ is removed in the five countries.

The Czech Republic approaches Western standards in most of the respects considered here. The fraction of the populace served by public water supply is the lowest in Slovakia while the level of sewerage and wastewater treatment is the poorest in Slovakia and Hungary (although the largest portion of towns without any treatment is found in Bulgaria). On the other hand, the "utility loop" is the greatest in Hungary, evidence of strongly unbalanced past policies favouring water supply development over sewer construction.

Per capita water supply (both total and domestic) is particularly high in comparison to Western countries. This arises from large losses from aged pipe networks and low water prices. The lowest per capita use is found in Hungary where water prices were raised earlier than in the other countries. The domestic supply rate is extremely high in Bulgaria.

The overall quantity of wastewater collected is practically equal to the amount of water supplied (however, large differences were shown on a municipality level). Reliable comparison between water supply and wastewater is impossible due to a lack of accurate measurements and sewerage flow augmentation by infiltration, stormwater flows, and industrial discharges. Furthermore, many water works supply not only the immediate municipality but also neighbouring areas. The sewerage systems frequently collect from different areas, and thus the water supply district and sewerage district often do not coincide. Overall, only half of the wastewater collected comes from domestic sources while industry produces about $30 \%$.

\section{Wastewater Treatment Needs of Rural Areas}

About half of the total population of the five countries lives in towns with fewer than 25,000 inhabitants. This indicates the need for a large number of small treatment plants. Rural communities, which number near 20,000 , form at least $30 \%$ of the total population but possess only a primitive level of water infrastructure development. There is generally a tendency to focus on water supply for rural villages and to neglect more costly wastewater collection and treatment. Such one-sided development tends to increase pollution in these areas. On-site wastewater treatment with septic systems was used frequently in the past. However, they were constructed under very lax control and inspection, causing a resistance as future applications are concerned. Overall, small communities form a major strategic issue in CEE countries. A cost-effective and sustainable strategy should be based on controlling the water consumption cycle on the household level, local disposal, recycling, reuse, and the application of small-scale, on-site, natural treatment as much as possible, depending on population density patterns and site specific conditions (implying that the construction of a sewer system should not be an automatic decision).

\section{Wastewater Treatment and Sludge Handling Infrastructure}

In all countries there is a strong tradition of using the activated sludge process in secondary wastewater treatment. The age of plants is not generally an issue: more than half were constructed after 1970. There are practically no plants providing nitrogen removal and few providing phosphorus removal.

Population-equivalent values of BOD, nitrogen, and phosphorus load a regenerally similar to those of Western Europe. Average influent values are around $260 \mathrm{mg} / \mathrm{l} \mathrm{BOD}, 38 \mathrm{mg} / \mathrm{l} \mathrm{TN}$, and $9 \mathrm{mg} / 1 \mathrm{TP}$ (under current water consumption rates). Country-specific concentrations depend on the rate of water supply, the composition of detergents, the contribution by industry, and data uncertainty. The latter is particularly problematic for TP and TN which, for example, are unrealistically low in the Bulgarian data. The level of nutrients in wastewater and the uncertainty in those levels will be important considerations in any future decisions to introduce nutrient removal.

The lack of adequate industrial pre-treatment is a problem in all of the,countries. In some cases, industrial wastes cause $\mathrm{BOD}$ or $\mathrm{COD}$ influent concentrations that are five times higher than in typical municipal 
wastewater. Industrial wastewater often contains toxic or other undesirable components, such as heavy metals, oils, toxic organic compounds, extremely acidic or alkaline wastes, and so forth.

There are many wastewater treatment plants which are overloaded by $100 \%$ or more. Upgrading these facilities is an important strategic consideration for the short term. At the same time, there are a significant number of plants which are not fully utilized for lack of supporting sewer systems, interceptor sewers, or pumping stations. The Northern Wastewater Treatment Plant in Budapest, Hungary, is an example of an underutilized facility. This shows another strategic consideration: the need to extend or upgrade missing infrastructure (to be driven by environmental considerations in the short run rather than by utility development alone), such that existing systems can operate at full capacity.

Many treatment plants are compromised by poor design, low quality, outdated equipment with high energy demand (e.g. aerators), inadequate control and monitoring systems, inadequate maintenance, and poor operations.

There are more than 1,000 partially constructed treatment plants in the five countries considered (a large portion of them in Poland). Most are significantly oversized - sometimes by as much as $100 \%$ - due to past practices in forecasting treatment needs. Forecasts were typically made by linearly extrapolating prior growth trends and with the assumption that water was free. With today's political and institutional changes, water and wastewater fees are being increased, the industrial structure is being altered, and the composition of detergents and other products is changing. For all these reasons, there are significant shifts in the quantity and quality of wastewater from what was assumed at the time of design. Additionally, new goals for future water management are evolving, and budgets are seriously constrained. Thus, there is a clear need to reevaluate planned treatment plants and redesign many of the plants selected for continued construction.

Renovation of water supply and sewer networks is a major and difficult expense for Western municipalities. The financial burden is much greater in the CEE countries, but infrastructure improvements are sorely needed. Water loss from water distribution networks is about 20 to $30 \%$, at the cost of a couple of hundred million USD annually in the five countries. The wastewater collection network is aged, poorly maintained, and typically includes combined storm and sanitary sewers. For example, half the sewers in Budapest were constructed before the second World War. Stormwater flows, groundwater infiltration, and illegal discharges contribute approximately 20 to $30 \%$ of the wastewater flow at a cost similar to the 500 million USD annual loss on the supply side.

Our analysis has identified an increasing gap from water supply through wastewater collection to treatment. The gap widens further with respect to the treatment of sludge. Data are insufficient to perform a systematic analysis; however, an educated guess is that about half of the sludge produced is not adequately treated and properly disposed. Often, sludges find their way back into the environment, reversing the environmental benefit intended from wastewater treatment in the first place.

The availability of sludge treatment facilities is limited. Anaerobic stabilization is used at only the larger wastewater treatment plants. Aerobic treatment is the typical technology at smaller plants. Dewatering capacity is generally insufficient. Sludge is disposed of in sludge fields, lagoons, landfills, agriculture, and elsewhere. For example, in Hungary about $50 \%$ of the sludge disposal is described as "temporary" without further specification. Inadequate industrial pre-treatment means that sludges are often contaminated by heavy metals and classified as hazardous waste, preventing final disposal. The various factors impairing the quality of sludge prevent its use as fertilizer or in energy production. Moreover, changes in environmental legislation also reduce sludge disposal options. For example, in Slovakia approximately half of the sludge now produced is used in agriculture (40\% is disposed of in landfill). However, new environmental guidelines and legislation will practically prohibit agricultural use (without considering the lack of anavailable short-term alternative). The major problem is caused by cadmium, which is limited to 13 milligrams cadmium per kilogram of dry solids (DS) in sludges to be composted. This limit can rarely be met under present conditions due to the lack of industrial pre-treatment. The same limit is $5 \mathrm{mg} \mathrm{Cd} / \mathrm{kg} \mathrm{DS}$ in Hungary (an unrealistically low value at present). As a comparison, the standard in Scandinavian countries JWST 30:5-B 
was $10 \mathrm{mg} \mathrm{Cd} / \mathrm{kg}$ DS until 1985. The current value is $4 \mathrm{mg} \mathrm{Cd} / \mathrm{kg}$ DS with the goal to lower it to $2 \mathrm{mg}$ $\mathrm{Cd} / \mathrm{kg}$ DS by 1995 . This example shows the importance of setting standards properly by evaluating alternatives, economic implications, and the time horizon of realizing planned changes.

\section{Legislation}

Water and wastewater charges were increased significantly in all five of the countries studied during the last few years. Charges in Hungary have now reached levels which realistically reflect the costs of the services, and have led to 20 to $30 \%$ reductions in water consumption (even though water meters are still missing in many apartments). The same is expected to happen soon in the other countries of the region. Reduced consumption is decreasing the hydraulic overload of existing wastewater treatment facilities and municipal wastewater is becoming more concentrated.

Pollution charges and fines have seen less change. New environmental legislation has yet to be passed into law in most of the countries covered by our analysis, and enforcement is minimal. Lax enforcement is a result of the ongoing institutional changes mentioned earlier. Within this enforcement and legislative void, industrial restructuring and privatization continue but with great need for well-designed policies and strong enforcement.

Parliaments in the CEE countries are overloaded by the need to pass new laws addressing all aspects of governance, not just environmental and water policy. Under these circumstances, hastily passed laws sometimes cause inconsistencies and new difficulties. For example, laws passed in Hungary in 1991 established goals requiring towns to show substantial progress by 1994 in developing water supply systems. However, there were no corresponding requirements concerning wastewater collection or treatment; those requirements are contained in draft environmental legislation which is unlikely to be approved before 1994 . Developing water supply systems without simultaneously addressing wastewater will further open the utility loop in Hungary, already the highest among the five countries considered here. A consequence will be further contamination of groundwater.

New systems of water-quality standards and stream classification are under discussion in all of the countries. The outcome will significantly influence future management practices. The former Czech and Slovak Federal Republic (C.S.F.R.) and Bulgaria depended upon receiving water standards for control of wastewater discharges (Hungary still uses regionally variable effluent standards). However, lenient standards and a lack of monitoring and enforcement provisions made these rules ineffective. Reacting to these earlier failures, the tendency today is to avoid ambient water-quality standards and instead adopt the very stringent effluent standards recommended by the European Community. Unfortunately, the budgetary consequences of these standards have not been fully realized and there is the widespread but mistaken belief that EC standards can be met "immediately". This attitude misses the process concept of the EC recommendations. Moreover,it ignores the practicality of what is likely to be a long process to approach the EC recommendations.

The process view is confirmed by new standards approved in 1992 in the C.S.F.R. (although the time horizon seems to be short). The municipal discharge standards set limits that are staged over time. Prior to the end of 2004, effluent concentrations must be less than $30 \mathrm{mg} / \mathrm{l}$ of BOD, $10 \mathrm{mg} / \mathrm{l}$ of ammonia-nitrogen, and $3 \mathrm{mg} / \mathrm{l}$ of total phosphorus in municipal discharges greater than a 100,000 population equivalent. Beginning in 2005, limits are tightened to $25 \mathrm{mg} / \mathrm{l}, 5 \mathrm{mg} / \mathrm{l}$, and $1.5 \mathrm{mg} / \mathrm{l}$, respectively. Standards are less stringent for smaller communities, and are perhaps less stringent than the EC recommendations. No limits are set for TN, but limits are set about ammonia due to concern for drinking water supplied from surface water. The C.S.F.R. permit system is based on the concept of combined standards. Both receiving water and effluent standards were set, with priority given to effluent standards. However, it is not yet clear how this policy will work in practice.

The management of municipal discharges requires tremendous investment. Unfortunately, none of these countries can afford to make the required investments, particularly over the next few years. Therefore, there 
is critical need for a well-designed, realistic, and cost-effective development strategy. This issue is discussed in the subsequent section.

\section{MAJOR ELEMENTS OF COST-EFFECTIVE WASTEWATER MANAGEMENT STRATEGIES}

Environmental and water quality management in developed countries is a relatively straightforward task. Frequently, strict effluent standards (e.g. EC requirements), willingness, and money are there to pay for a safe environment. Actually, economic implications of meeting standards and water quality goals are rarely or never addressed. However, under tight financial conditions of the CEE region this policy cannot be followed; environmental goals should be translated into budgetary terms to be able to judge the rationale of a plan. In fact, the question can and should be formulated differently, i.e. how can CEE countries achieve the largest improvement in the state of the environment from the scarce financial resources available? This approach then induces a number of additional questions. Which actions to take and in what sequence? Where and when to act? Which goals to set, or what quality states to anticipate? Which treatment technology to select (and how to estimate the future amount of wastewater to be processed)? We will subsequently deal with some of these questions.

\section{Demand Management and Closing Material Cycles}

As can be seen from Table 1, the level of wastewater collection is significantly higher than that of treatment. Thus, the emphasis should initially be placed on upgrading wastewater treatment facilities (including sludge handling) rather than developing new water distribution and sewer networks. In a broader sense, this implies upgrading unbalanced facilities to their maximum capacity. This will close material cycles as much as feasible. Properly set water tariffs and other incentives will reduce both domestic and industrial wastewater flows (which in turn increase the strength of the raw wastewater). Ongoing industrial changes also significantly influence the amount and composition of municipal wastewaters. As a result of the abov ealterations, many highly overloaded plants have already been shifted back nearly to the design capacity. This has led to BOD effluent improvements from around $80 \mathrm{mg} / \mathrm{l}$ to $30 \mathrm{mg} / \mathrm{l}$ or less.

Under the present transition, future wastewater flows are hard to predict. Thus, the advice is to perform upgrading and/or new construction according to needs which can be safely estimated. Further plant extension should be done only after monitoring the changes. Mistaken estimates of future capacities can result in wasted investments (it suffices to mention that the investmentcost of $1 \mathrm{~m}^{3} / \mathrm{d}$ wastewater treatment capacity is in the order of 500-1,000 USD).

\section{River Basin Least-Cost Approach}

The next important element in developing a cost-effective strategy is to apply a river basin approach, leading eventually to regionally variable effluent standards. The idea is to define ambient water quality goals according to actual water uses (as much as possible, see later) and transfer them subsequently to effluent standards to be monitored and enforced in practice.

Often, safe water supply, eutrophication control, fishing, irrigation, and the protection of ecosystems, provide enough basis to specify ambient criteria for traditional components such as $\mathrm{DO}, \mathrm{BOD}_{5}, \mathrm{NH}_{4}-\mathrm{N}$, $\mathrm{NO}_{3}-\mathrm{N}, \mathrm{TP}, \mathrm{Chl}-\mathrm{a}$, and others. These are components for the modeling of which more than twenty-five years of experience are available (see e.g. the QUAL model family of the U.S. EPA). Thus, BOD 5 , TN, and TP site emissions (as well as their various fractions and compounds) and spatially (and temporally) variable ambient water quality (characterized e.g. by the earlier mentioned components) can be linked. In this manner, the impact of various load reductions can be assessed, or in a control policy formulation, the "optimal" strategy to meet receiving water quality goals by minimizing the costs can be determined. The regionally variable effluent standards (or technology types) are side results. 
Such water quality management models (now called decision support systems) have been known since the early seventies (see e.g. Thomann, 1972, Hahn and Cembrowicz, 1981). Their past application did not receive significant attention in Western practices. The reasoning was manifold: "poor" performance of models, large computational efforts necessary, the difficulty of monitoring and enforcing ambient water quality indicators and/or corresponding, regionally variable effluent standards, etc. However, today very few or none of the above arguments are still valid. At least thea bove methodology can be employed for strategic thinking and for the development of a robust range of river basin least-cost policies.

As an illustration, we refer to the case of the Nitra river basin in Slovakia (see Somlyody et al., 1994). The investment cost requirement of a policy based on Slovakian effluent standards is around 30 million USD. To meet recommendations of the European Community would cost about two to three times more. A least-cost policy corresponding to acriterion $\mathrm{DO}_{\min } 5 \mathrm{mg} / \mathrm{l}$ (the present value is around $2 \mathrm{mg} / \mathrm{l}$ ) leads to only 15 million USD investment requirement in spite of the minor deviation (less than $20 \%$ ) from the ambient water quality of the Slovakian effluent standard based strategy (in terms of $\mathrm{DO}, \mathrm{BOD}_{5}$, and $\mathrm{NH}_{4}-\mathrm{N}$ ). A DO $\min 4 \mathrm{mg} / \mathrm{l}$ policy would be even cheaper by 10 million USD.

The analyses have shown that the economic consequences of setting standards are strong and non-linear. The range of expenditures is extremely broad depending on the policy formulation which indicates significant saving possibilities to be recognized in the practice of CEE countries.

There are other cases when water uses and ambient water quality in a region are decoupled due to past water management policies (e.g. water of high quality was transferred from other resources). Under such conditions it is difficult to set goals, but in fact such situations clearly indicate that urgent actions are not needed and the priority is low. Thus, regionally variable standards and/or their scheduling are again important.

\section{The Role of Dilution and Inland Sea Problems}

The setting of water quality goals and priorities is difficult for river scharacterized by extreme dilution rates. For instance, more than $30 \%$ of the municipal WWTPs in the five CEE countries discharge into streams having a low flow less than $2 \mathrm{~m}^{3} / \mathrm{s}$. The average $\mathrm{BOD}_{5}$ value is about $25 \mathrm{mg} / \mathrm{l}$. One-fourth of these streams act as sewage canals, and any water uses are out of the question. While in the long run such a situation must not be accepted, the short-term policy dictated by scarce resources would often suggest no action (obviously depending on downstream water quality).

About $10 \%$ of the WWTPs discharge to rivers of high dilution $\left(>100 \mathrm{~m}^{3} / \mathrm{s}\right)$ and relatively good quality (from the viewpoint of mass, the contribution of this cluster is higher). For such cases, uniform emission reduction, improper standard setting, and scheduling can lead to serious over-expenditures. For instance, the construction of an advanced wastewater treatment plant in Szeged (Hungary) with $\mathrm{P}$ and $\mathrm{N}$ removal would not improve the quality of the Tisza River $\left(>200 \mathrm{~m}^{3} / \mathrm{s}\right.$ ) by more than $5-15 \%$ depending on components considered (the present quality is characterized by $\mathrm{DO}=6.3 \mathrm{mg} / \mathrm{l}, \mathrm{BOD}_{5}=4.7 \mathrm{mg} / \mathrm{l}$, inorganic $\mathrm{N}=3.8 \mathrm{mg} / \mathrm{l}$ and $\mathrm{TP}=0.32 \mathrm{mg} / 1 ; 90 \%$ values in 1991). The high investment cost (around 60 million USD) is definitely not justified in the near future.

Budapest is another example where a large portion of wastewaters enter the Danube without any treatment (the level of biological treatment is $20 \%$ ). Such a setting is unacceptable but the real issue is the technology selection. The quality of the Danube downstream of the capital is similar to that of the Tisza (better for DO and somewhat worse for the three other components among which BOD is subject to fast improvement along the river due to self-purification). Depending on the technology choice (incorporating the upgrading of existing facilities and the construction of new ones ranging from chemically enhanced mechanical treatment to an advanced one with $\mathrm{P}$ and $\mathrm{N}$ removal, see later), the difference in water quality improvement is not more than $1 \mathrm{mg} / 1,0.5 \mathrm{mg} / 1$, and $0.1 \mathrm{mg} / 1$ for $\mathrm{BOD}_{5}, \mathrm{TN}$, and $\mathrm{TP}$, respectively. Such a difference is practically negligible from the viewpoint of local water quality concerns (including recreational usage and the protection of bank-filtered resources). However, investment costs are strikingly deviant from each other. 
The difference is about a thousand million USD which is two to three times more than the cost of solving wastewater treatment in all the towns of the country. Thus, the policy choice and its scheduling are again crucial issues.

The solution of large international problems of seas such as the Baltic or Black Sea requires the reduction of loads carried by rivers (as compared to concentration improvements), and thus dilution does not play a role. The resulting regional issue is rather different from local problems of individual countries that lead to differing priorities (difficult to define due to uncertainties in estimating the contribution of various upstream emissions to total emissions at the mouth) and primary components to be controlled (nutrients as contrasted to organic material, among which the marginal costof $\mathrm{N}$ removal is particularly high).

Managing local and regional problems is a difficult and challenging task. In fact, under the present financial constraints, these tasks may not be handled simultaneously. The solution of local problems should have higher priority, followed by actions driven by regional concerns in the frame of a well-designed international setting.

\section{Cost-Effective Wastewater Treatment and Upgrading Methods}

The pre-condition of developing a regional least-cost water pollution control policy satisfying ambient water quality requirements is to have a sequence of well-proven technology alternatives with known costs and pollutant removal rates (expressed in terms of components mentioned before).

Biological and chemical treatment (both incorporating mechanical units) have a history of about one hundred years. Many good experiences and traditions have been collected and developed, and lessons have been learned from failures.

Cost-effectiveness in terms of BOD removal is essentially the same (2-3 USD $/ \mathrm{kg}$ BOD for both methods). This is true regardless of whether the system applies high- or low-load activated sludge process or uses high or low dosage for chemical treatment corresponding to "primary precipitation" and "chemically enhanced mechanical (primary) treatment", respectively (see Henze and Odegaard, 1994, for details). The evaluation, however, should be done with care, since chemical treatment generally does not exceed 70\% BOD removal. However, P (and heavy metal) removal is much higher than for biological treatment. At the same time, sludge production, area, energy, and chemical requirements, as well as operational features, can be quite different. Biological treatment cannot be excluded if nitrification and denitrification are important, while chemical treatment has been driven primarily by phosphorus removal during the past two decades. The two basic methods relying upon different principles complement each other, and the future wastewater treatment likely will be based on the combination of the two (Hahn, 1990).

The combination of the two methods leads to a number of benefits of high importance when handling multiple pollutant issues. Chemical dosage (even in low qu antity) increases BOD, COD, and SS removal of the primary sedimentation tank (Morrissey and Harleman, 1990), and thus the biological unit can be downsized, or more nitrification can be achieved from the same volume. Chemical dosage also significantly increases the surface overflow rate (OFR) of the primary unit (practically doubles it). This again can lead to size reduction for new designs. The two features together (increase in BOD removal and OFR) make a chemically enhanced first stage particularly attractive to expand the capacity of existing, overloaded secondary biological treatment plants. Its extent can achieve $80-100 \%$, which can be utilized according to capacity limits and extension possibilities of the final clarifier and sludge processing (see later).

The cost-effectiveness of combined biological/chemical methods is significantly higher from a multiple pollutant viewpoint than that of the two methods individually, and there is an increased flexibility to achieve desired effluent quality levels (according to requirements of receiving waters). Moreover, the chemical upgrading of existing, overloaded secondary biological treatment plants and/or primary ones is far more cost-effective (including sludge treatment) than any other alternatives, even if we use BOD removal as a single measure. 
Thus for today, a large number of technology alternatives are well explored, together with sludge handling options (for removal rates and unit costs see Henze and Odegaard, 1994). They include mechanical, chemical, and biological treatment (and their different versions) and biological-chemical treatment with differing levels of $\mathrm{N}$ removal (including a partial one). The biological unit can be based on the activated sludge process (which is the present practice in the CEE region) or biofilm (which may become the common practice in the future).

Therefore, the number of treatment alternatives can be rather large for a given situation, particularly if we also consider a combination of upgraded existing facilities and the construction of new ones (together with their scheduling).

\section{Multi-Stage Development}

Treatment plants are constructed in the West in one step, very quickly. This may not be possible in the CEE region if we consider plants corresponding to the $\mathrm{EC}$ requirements as final, long-term objectives. An additional attractive feature of the family of combined biological-chemical technologies is that they can be designed and built (or used for upgrading) in a phased, multi-stage fashion (see Somlyody, in press).

The first step is a chemically enhanced mechanical (or primary precipitation) plant. This can be expanded later on as money becomes available to a chemical-biological plant (utilizing down-sizing possibilities). The final stage is the addition of denitrification in sensitive regions, which scheduling is justified by the high marginal cost of $\mathrm{N}$ removal (for details see Henze and Odegaard, 1994).

The idea of staged project development is often used in water resources management. The purpose is to realize capacity extensions, meeting future needs while minimizing the present value of future expenditures. An engineering economics analysis can justify that phased upgrading or construction can significantly increase average BOD, TP, and TN cost-effectiveness (for the life-time of the project) within realistic ranges of the life-time, interest rate, and inflation rate, respectively (see Somlyody, in press). Moreover, the starting investment cost requirement currently the primary limiting factor, is also significantly reduced.

\section{An Example for Cost-Effective, Low Dosage Chemical Upgrading}

The North Budapest Wastewater Treatment Plant is a traditional activated sludge plant with a $140,000 \mathrm{~m} / \mathrm{d}$ design capacity (grit removal, primary clarifier, aeration basin, final clarifier, sludge dewatering, and landfill disposal).

To test the applicability of low dosage chemical upgrading, a three-week full-scale test was performed adding $30 \mathrm{mg} / \mathrm{FeClSO}_{4}$ prior to the primary clarifier and one of the two operating trains was overloaded by more than $60 \%$ (see Murcott et al., in press). Effluent water quality remained unchanged (e.g.COD $=75$ $\mathrm{mg} / \mathrm{l}$ ) except for $\mathrm{TP}$ and $\mathrm{Cr}$ which improved significantly (TP $=2 \mathrm{mg} / \mathrm{l})$. Under the same compressor operation as earlier, the oxygen level increased considerably in the experimental aeration tank. There was no detectable change in the sludge production and $\mathrm{pH}$ values. The amount of $\mathrm{FeClSO}_{4}$ used for sludge dewatering could be reduced, indicating that chemical usage within the plant can be further optimized.

The investment cost of the implementation leading to a reliable interim technology for treating 220-250,000 $\mathrm{m}^{3} / \mathrm{d}$ wastewater (including additional dewatering facilities) is not more than a couple of million USD. This should be contrasted to several hundred million USD requirement for a plant corresponding to EC directives (the cost estimate of a recent design for $460,000 \mathrm{~m}^{3} / \mathrm{d}$ average future flow - a hardly predictable value at present - with $\mathrm{P}$ and $\mathrm{N}$ removal and anaerobic digestion was above a thousand million USD).

The example shows that modest investments can lead to significan tenvironmental benefits and that the clever utilization of existing facilities is an important element of developing multi-stage water quality control policy programs corresponding to gradually tightened standards (eventually approaching those of the $\mathrm{EC})$. 


\section{IMPLEMENTATION CHALLENGES}

In the West, many experiences have been gained in water quality management in the course of the past 2030 years. A significant portion of them are very useful for the CEE region. However, it is unlikely that an imitation of Western environmental policies can lead to a success due to outlined political, institutional, economic, and social conditions that deviate strongly from those of the West a couple of decades ago. In other words, a short-term strategy based on uniformity (incorporating standards, emission reductions, financing, enforcement, etc.) is likely to fail. It is believed, thus, that the only choice is a non-uniform policy, the major elements of which are upgrading of the existing facilities, cost-effectiveness, the application of a river basin approach, regionally variable standards, proper technology selections, and phased investments, all depending on site-specific conditions.

The implementation of such a strategy is difficult, and admittedly it is not yet known to what extent it can be done, particularly under the present and sometime is rather confusing institutional settings (see earlier). It is relatively straightforward to offer a number of wastewater treatment methods and cost-effective alternatives, but the impact on technology choice in practice is a much more difficult issue. It requires, among other things, solid technology transfer and demonstration projects, the preservation of good traditions and the foundation of new ones, and the development of (new) local expertises and water industries. Also, it necessitates the setting of regionally varying standards (effluent, ambient, or a combination), which tighten over the transition period (so that eventually they become uniform) thus opening avenues for selecting technologies according to principles outlined earlier. Stemming from phased development, legislation and enforcement should be characterized by flexibility and rigidity, respectively (i.e. gradually tightened standards should be enforced strictly) which in itself seems to be contradictory.

Financing also raises a number of questions, and the situation strongly deviates from that of a centrallyplanned economy (see Kindler, 1994, for further details on issues of implementation). As long as municipalities can pay for the technology selected (even if it is a showcase treatment plant), there are no problems. However, this is seldom the case: subsidies or loans from environmental (or water) funds are unavoidably needed (in some countries state subsidies unfortunately still exist). Under such conditions it does matter for which technologies these subsidies are used, how many treatment plants can be upgraded and constructed in a country, and whether the plants are really becoming self-sufficient on the income from sewage charges (and pollution fines, depending on the actual system of economic instruments). Financing schemes should be developed in such a way that they strongly enforce the realization of feasible strategies and regional river basin policies.

All this means that the consequences of economic transition should be reflected by the totality of legislation and associated institutions. We face a long and difficult process which requires much innovative thinking. The challengeis high. There is no guarantee that the end will be a success, but otherways offer much less hope.

\section{CONCLUSIONS}

CEE countries are going through unique political, economic, and social changes associated with the heritage of serious pollution problems from the past. The solution to these problems requires tremendous costs which are not in harmony with resources available (the per capita GDP is one-fifth to one-tenth of developed Western European countries and present trends are still negative). Environmental and water quality management face a much longer transition period (2-3 decades) than generally believed.

Under the present conditions the imitation of Western environmental policies is likely to fail. The suggested strategy here is based on careful priority setting, cost-effectiveness, and least-cost actions in the short run, which should then gradually be expanded over the transition period as the economy improves. The process requires a nearly permanent updating in legislation, institutional systems, and financing schemes, as well as lots of innovative thinking. 
In industry and agriculture, the opportunity of coupling environmental management and sectoral restructuring should be utilized. The introduction of advanced, clean technologies should be a key element of the policy. Municipal emissions form a different problem. Investment requirements are huge. The goal should be to develop a cost-effective strategy which does not constrain economic transition.

The overall level of water supply is good, and on average, sewage collection is adequately developed in CEE municipalities. However, the level of sewage treatment is poor. Less than $50 \%$ of the wastewaters receive secondary treatment. There are many treatment plants which are overloaded by $100 \%$ or more. The number of larger uncompleted treatment plants exceeds one thousand.

Major elements of cost-effective development strategies are summarized as follows:

Demand management should be improved (including reduced water consumption), material cycles should be closed as much as possible, and the wastewater treatment facilities should be upgraded to match the level of sewerage.

Regionally variable effluent (and/or ambient) water quality standards should be used which reflect water uses, local conditions, established and available wastewater treatment technologies, and financial constraints. Standard setting should not be driven by a desire to mimic standards in developed Western European countries. In the short run, less stringent criteria should be established and replaced with gradually tightened standards as economic conditions improve.

Standards in the short run should be set on the basis of least-cost river basin policies and proper economic instruments should be introduced to enforce these policies.

Cost-effective wastewater treatment technologies should be selected for upgrading and new construction alike. A number of combined biological-chemical processes can be applied depending on the actual conditions. The low-dose chemical upgrading of overloaded primary and secondary (biological) plants is an attractive alternative requiring minimal investments.

Wastewater treatment plants are proposed to be developed in a multi-stage fashion. Nitrogen removal is not recommended in the short term due to large marginal costs (except in a few highly sensitive regions), but designs should consider its eventual accommodation.

\section{REFERENCES}

Environmental Action Programme for Central and Eastern Europe (1993). Document submitted to the Ministerial Conference, Lucerne, Switzerland, The World Bank.

Hahn, H. H. (1990). Quo Vadis Chemical Treatment? In: Chemical Water und Wastewater Treatment, Hahn, H. H. and Klute, R. (Eds). Springer-Verlag, Berlin.

Hahn, H. H. and Cembrowicz, R. G. (1981). Model of the Neckar River, Federal Republic of Germany. In: Models for Wuter Quality Management, Biswas A. K. (Ed). McGraw-Hill Inc, New York, 158-221.

Henze, M. and Odegaard, H. (1994). An Analysis of Wastewater Treatment Strategies for Eastern and Central Europe. Wut. Sici. Tech. 30(5) (this volume).

Kindler, J. (1994). Some Thoughts on the Implementation of Water Quality Management Strategies for Central and Eastern Europe. Wat. Sci. Tech. 30(5) (this volume).

Morrissey, S. P. and Harleman, D. R. F. (1990). Chemically Enhanced Wastewater Treatment. MIT Ralph M. Parsons Laboratory, Report No. R90-14.

Murcott, S., Somlyody, L., Knolmar, M. and Botond, Gy. (in press). Chemical Upgrading of the North Budapest Wastewater Treatment Plant. International Institute for Applied Systems Analysis, Working Paper.

Somlyody, L. (in press). Municipal Wastewater Treatment in Central and Eastern Europe: Present Situation and Cost-Effective Development Strategies. The World Bank.

Somlyody, L., Kularathna, M., and Masliev, I. (1994). Development of Least-Cost Water Quality Control Policies for the Nitrat River Basin in Slovakia. Wat. Sci. Tech. 30(5) (this volume).

Thomann, R. V. (1972). Systems Analysis and Water Quality Management. McGraw-Hill, New York. 

